Public Abstract

First Name:Munashe

Middle Name:

Last Name:Chigerwe

Adviser's First Name:Jeff W. Tyler

Adviser's Last Name:Kristopher J. Hagglund

Co-Adviser's First Name:John R.Middleton

Co-Adviser's Last Name:Jim Spain

Graduation Term:SP 2008

Department:Pathobiology Area Program

Degree:PhD

Title:

\title{
EFFECT OF COLOSTRAL ADMINISTRATION PRACTICES ON SERUM IMMUNOGLOBULIN CONCENTRATIONS IN DAIRY CALVES
}

The type of placenta in cattle allows minimal transfer of immunoglobulins which are essential for passive immunity to different pathogens in the newborn calf. Thus calves acquire these immunoglobulins through ingestion of colostrum. Despite the accumulated understanding of the factors which affect the transfer of immunoglobulins and their importance, approximately 35-40\% of US dairy calves have inadequate passive transfer. Thus, either the total immunoglobulin mass being fed to the calves is inadequate or colostrum administration practices require more concerted effort than most farmers perform. The main objectives of the presented study were to determine the role of immunoglobulins present in the calfâ€ $€^{\mathrm{TM}} \mathrm{s}$ blood before feeding colostrum, determine the optimum method to assess the concentration of colostral immunoglobulins and evaluate factors affecting transfer from colostrum to the calf. There was no apparent link between presence of immunoglobulin in the blood of the calf and common pathogens known to be transmitted across the placenta. The electronic refractometer had more advantages over the hydrometers or weight of first milking colostrum as a test method to identify colostrum samples with low lgG concentrations $(<50 \mathrm{~g} / \mathrm{L})$. At least 150 to $200 \mathrm{~g}$ of colostral immunoglobulin is required for adequate passive immunity transfer in tube fed calves. Calves ingesting $3 \mathrm{~L}$ at first feeding and $3 \mathrm{~L}$ at 12 hours was resulted in a majority of calves receiving adequate immunity through colostrum. 